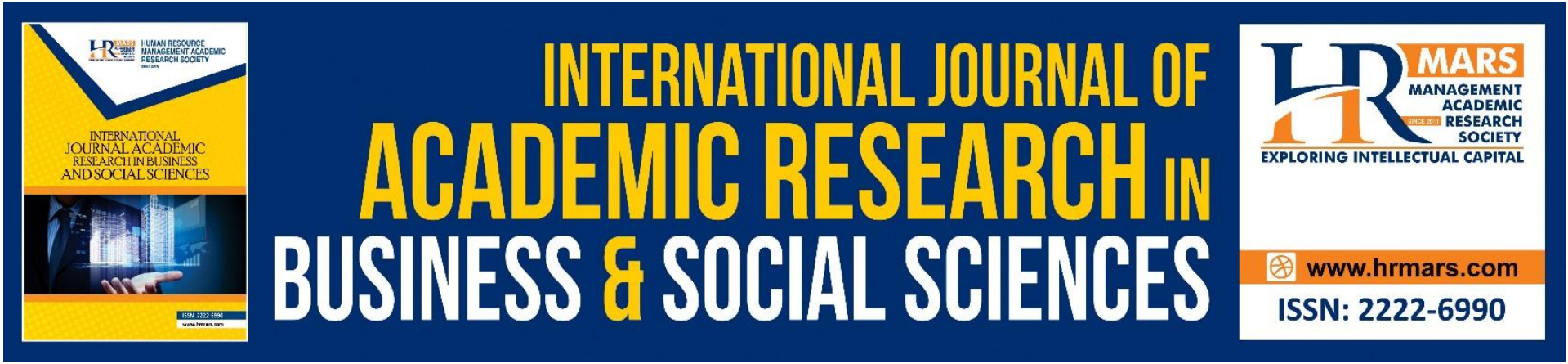

\title{
Code-switching of English-French in French Kissing Novel by Catherine Sanderson
}

\section{Amirah Syazwani Roslan \& Omrah Hassan @ Hussin}

To Link this Article: http://dx.doi.org/10.6007/IJARBSS/v11-i12/11895

DOI:10.6007/IJARBSS/v11-i12/11895

Received: 07 October 2021, Revised: 09 November 2021, Accepted: 27 November 2021

Published Online: 20 December 2021

In-Text Citation: (Roslan \& Hussin, 2021)

To Cite this Article: Roslan, A. S., \& Hussin, O. H. @. (2021). Code-switching of English-French in French Kissing Novel by Catherine Sanderson. International Journal of Academic Research in Business and Social Sciences, 11(12), 1524-1539.

\section{Copyright: @ 2021 The Author(s)}

Published by Human Resource Management Academic Research Society (www.hrmars.com)

This article is published under the Creative Commons Attribution (CC BY 4.0) license. Anyone may reproduce, distribute, translate and create derivative works of this article (for both commercial and non0-commercial purposes), subject to full attribution to the original publication and authors. The full terms of this license may be seen at: http://creativecommons.org/licences/by/4.0/legalcode

Vol. 11, No. 12, 2021, Pg. 1524 - 1539

Full Terms \& Conditions of access and use can be found at http://hrmars.com/index.php/pages/detail/publication-ethics 


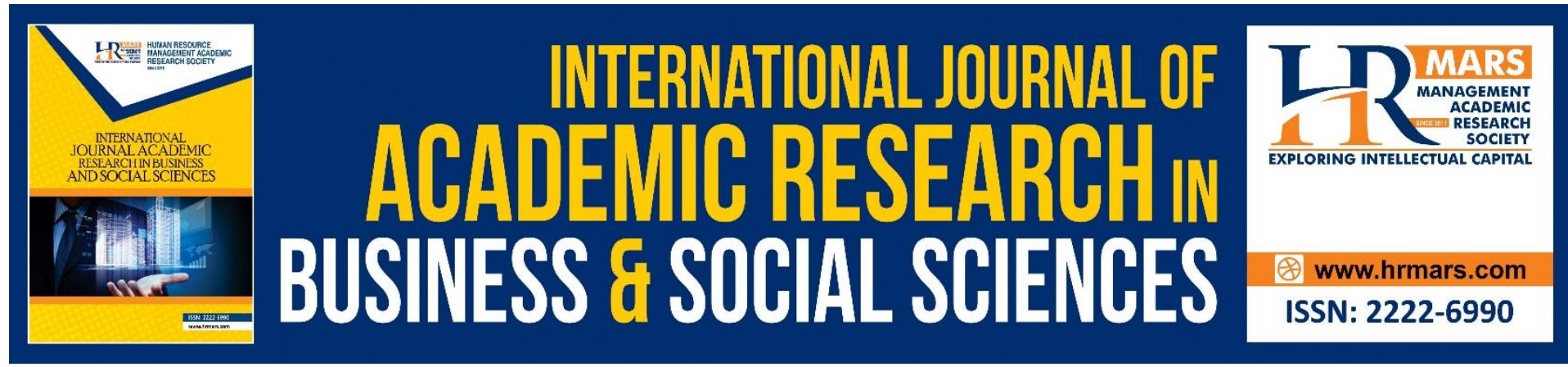

\title{
Code-switching of English-French in French Kissing Novel by Catherine Sanderson
}

\author{
Amirah Syazwani Roslan \& Omrah Hassan @ Hussin \\ Faculty of Modern Languages and Communication, Universiti Putra Malaysia 43400 UPM, \\ Serdang, Selangor, Malaysia \\ Email: amirahsyazwani96@gmail.com,omrah@upm.edu.my
}

\begin{abstract}
The tremendous development of today's globalization has resulted in the employment of code-switching which was perceived as the usage of more than one language in a particular discourse among individuals. Consequently, the trends of applying multiple languages in a written context especially in novels are seen to be increasing over years. Apart for leisure purposes, novels also allowed us to discover varied language phenomenon including codeswitching due to its non-specific writing styles. This study investigated code-switching of English-French used in the narrative and dialogues of the French Kissing novel by Catherine Sanderson. Simultaneously, through a descriptive qualitative method, code-switching analysed in the novel was distributed, analyzed and described accordingly. Firstly, this study applied a theoretical framework pioneered by Poplack (1980) namely tag code-switching, intrasentential code-switching and intersentential code-switching. The results of the initial review found that intrasentential code-switching has the highest frequency $(79.34 \%)$, followed by intersentential code-switching (13.64\%) and tag code-switching (7.02\%). Moreover, this study also coded the factors influencing code-switching in the novel according to Holmes (2008). The findings demonstrated that the three highest factors contributing to code-switching are switching for effective function, topic as well as participants, solidarity and status. Meanwhile, lexical borrowing and metaphorical switching were the least factors of the code-switching phenomenon in the novel. Generally, the findings explained code-switching as an effective communicative strategy which are beneficial to make the novelist' intended meaning explicit and to preserve the engagement among the characters. Besides, codeswitching has occasionally remarked the discourse practiced among the local society in France. Finally, further studies are suggested to be explored in depth through other written media precisely, novels under different perspectives.
\end{abstract}

Keywords: Code-Switching, Types, Factors, Novel, English, French.

\section{Introduction}

Languages were assigned as an essential communicative instrument that allows us to undergo comprehensive discussion with society. Precisely, in a language, there is a collection of codes which was called vocabulary that has been recognized by a group of people (Baron et al., 1997). Furthermore, languages have rapidly experienced changes throughout the 
globalization era as it has been affected by the massive development of global transportation, economy, communication technology and information has resulted in the rapid changes of languages. Hence, this has resulted in an increasing amount of interaction among people around the world. To allow a varied communication process, most people comprehend and practice other languages except their native language. Under language studies, this phenomenon was addressed as code-switching which can be explained as an individual's action to alternate between two or more linguistic repertoires in the middle of a discussion between a group of individuals who acquire more than one language in common, Paramasivam Muthusamy (2010). Simultaneously, the practice to infuse foreign languages with our native languages or dialects is common and can be taken in many forms by the Malaysian. As cited in Mahmor, et al (2016), it is conventional for a multilingual nation like Malaysia to perceive two or more languages, precisely, Malay-English; other Malay-dialects; English-other foreign languages. Next, this communication skill was beneficial to enrich their interpersonal communication skill with others, (Cao, 2016). This has made code-switching a choice of the society including those who work in creative industries, precisely, the novelist in registering code-switching as their communicative strategy in their writing has shown inclined trends by years. Therefore, the subject matter for this study is code-switching contained in a fiction English novel entitled French Kissing which particularly uses French as the second communicative instrument in its writing composition. In general, code-switching is utilized by bilingual/ multilingual individuals (Wardaugh, 2006). However, instead of bilingualism, this paper has listed out other factors producing code-switching in the selected novel.

\section{Literature Review}

Code-switching was captured as a vital subject matter to discuss as it has been recognized as a natural language progression in usage among individuals around the globe. In general, this language practice can be defined as the bilinguals' capability in manipulating two or more language repertoires within a particular topic of discussion. This correlates with Ganji et al (2019) that stated bilingualism has normalized code-switching in today's communication process. For instance, it has allowed the local society to develop their knowledge and capability to alter foreign language other than their native language in daily interaction activities. Plus, they also dedicated code-switching in all formations of language alternation including intersentential code-switching, intrasentential code-switching as well as borrowing. In addition, Verreyt et al (2016); Muhammed (2017); Wang \& Mansouri (2017) assert the code-switching phenomenon presents bilingual creativity but not a form of linguistic barrier that destruct an interaction process.

In addition, code-switching can be expressed as a language practice that corresponded to the relationship between the role of the speakers and the function of the languages used. In detail, the role dedicates to the individual who is using the language meanwhile the language's function indicates what the speakers aim to accomplish in their communication process. This scenario can be recognized as sociolinguistics under the language domains. According to Ningsih \& Setiawan (2021), "this field of studies analyze social aspects of language mainly differences in social factors". While reviewing the code-switching phenomenon taking place in various levels of sociolinguistics and multicultural circumstances, multiple researchers have identified this language phenomenon with regarded to the related situation in which the present study was proclaimed. Firstly, Bhatti et al (2018) have 
suggested analytical research that emphasizes code-switching was produced by the relationship of language structures and the interlocutors' mannerisms. Her findings discovered the dependent interaction process in a classroom was the topic of discussion, the outcome as well as the learners'/ students' acts in processing the information conveyed by the speakers/ teachers. This scenario is shown to carry the methodical functions of codeswitching which emphasizes the language-related functions and social functions of codeswitching. Plus, she also highlighted the alternation technique of numerous languages helps to give instructions or dealing with the emotional side of the others. As a result, codeswitching has discrete language formations that are clear and concise. Not only that, codeswitching accommodate continuity besides and did not interfering with any individuals' conversation Rusli et al (2018); Anggarukma \& Winaya (2019). For instance, the language phenomenon allows the interlocutors to carry out certain messages, values, attitudes as well as emotions in their speech which are beneficial to maintain the engagement with the listeners and inclined the impact of the context.

Moreover, the results found from the previous studies showed code-switching is seen frequently in various levels of communication. Simultaneously, this language phenomenon did not only undergo on the basic range of interaction platforms but was also regulated by various parties in the professional sectors including those who work in creative industries like the novelist. This corresponds with Yusuf et al (2018) who asserts code-switching is a common language practice that can be found in most parts of those literary works including the title, dialogues or narration. Simultaneously, novels are a form of writing media that reflect reallife situations among the characters (Akhtar et al., 2020). In detail, it allowed the readers to entertain themselves through whatever moment they desire, while the writer can present their ideas through the plots and demonstrated creativity by their writing styles including the language choice like using the code-switching phenomenon in a particular novel. As a result, code-switching practices have also attracted the novelists to use it as their communicative indicator to engage the ideas of their creative compositions with society. This corresponds to (Tawfiq \& Qararia, 2018; Anggraeni \& Dewi, 2020). argued code-switching was not only beneficial for entertainment purposes but also an advantageous linguistic and cultural implementation by bilinguals as a medium to write a text, especially novels using two different linguistic repertoires. For instance, the usage of the foreign language has been domesticated and enrich with linguistic items of local culture which have resulted in the globalization of the particular local culture, traditions and heritage. Simultaneously, Roslan (2020) exposed this language phenomenon helps to facilitate functions of the foreign language in a novel. In detail, the usage of the French language in an English novel has elevated French communicative functions which occasionally helps the novelist to engage her ideas using two different linguistic repertoires in the creative writing. For example, the usage of French terms revealed the background of the novel that takes place in Belleville, France.

Not only that, bilingualism which emphasizes the capability of speakers to enroll two languages in a particular discourse has become one of the key features in sociolinguistic studies as mentioned above. However, previous researchers have underlined multiple stimuli which resulting in this language phenomenon. This can be seen when there are several methodical works have been performed to discover the factors of code-switching in depth. This has been outlined by Maros et al (2016); Asbullah et al (2017) exposed code-switching as account due to the distinction of situations and context among a group of people. For 
instance, the individuals' usage of code-switching in their daily conversations was made up by the language incompetency, solidarity and expressing mannerisms among them. This corresponds to Paramasivam et al (2020), code-switching is a type of language phenomenon that was influence by multiple reasons which indicate a comprehensive communication process within a particular discussion. In detail, code-switching is produced to ease alternation in one language, conserving privacy, keeping away ambiguity and misunderstanding, presenting intimacy, individual's preference to speak their mother tongue and unfamiliarity with similar words or expressions in the second language. Consequently, this language phenomenon was also promoted by the individual's social factors and social dimensions which included their surroundings, status, prestige, educational background as well as a power relation.

To sum up, considering the listed reason above, this paper aims to carry out further research regarding the code-switching phenomenon, particularly, the types and the factors in the French Kissing novel. The present research is expected to present a detailed insight into code-switching through a written text, particularly, a fiction novel. An English novel entitled French Kissing novel by Catherine Sanderson was selected as the research material. She is a British citizen who has live in France for 13 years for work purposes. In detail, while working as a bilingual secretary in Belleville, she has created a blog called Petite Anglaise and simultaneously become a novelist. Next, the ability of a novelist to demonstrates multiple social segments can be beneficial to enhance the readers' interest including the usage of certain language used among the characters in the creative writing. Based on this background, all of the dialogues that contained the code-switching of English-French among the characters in the selected novel have been analyzed, precisely, intrasentential code-switching, intersentential code-switching and tag code-switching. Consequently, this paper will also discuss the factors of the code-switching phenomenon in the novel. The listed purposes are observed throughout the situations undertaken in the selected research material.

\section{Research Objective}

To identify the types of code-switching of English- French contained in the French Kissing novel.

To analyze the factors that embody the code-switching phenomenon among the characters in the selected novel.

\section{Methodology}

The present study follows the qualitative methods of descriptive design. According to Abu Bakar \& Dahlan (2017), a qualitative research design gave out a comprehensive explanation regarding a subject matter which are gained through the corpus analysis procedure that presents visual representations of observable data. To obtain the underlined purpose of this study, the code-switching phenomenon of English-French in the French Kissing novel which was published in 2009 has been analyzed. In total, the creative work comprises 27 chapters with 365 pages. Next, the research material is a fiction novel which is defined as the art of representing human life through writing compositions as mentioned by Leavy (2016). This corresponds with the novel's storyline which demonstrating the life of a British girl named Sally Marshall in Paris, France. Not only that, as mentioned in the reviewed literature, bilingualism is considered as the main medium that developed code-switching. Therefore, the novel was chosen because it was written by a popular bilingual novelist, 
Catherine Sanderson who has a high proficiency in English and French. Furthermore, the data has been classified under the three types of code-switching as promoted by Poplack (1980). In detail, the dialogues contained code-switching of English-French will be administered into different categories in a table, precisely, intrasentential code-switching, intersentential codeswitching and tag code-switching. Plus, the gathered data has been distributed into different factors of code-switching in a table to attain the present study nature. The researchers analyzed the factors influencing the usage of this language phenomenon among the characters in the literary writing based on Holmes (2008). In particular, there are five factors of code-switching namely, (1) participants, solidarity and status, (2) topic, (3) switching for effective functions, (4) metaphorical switching and (5) lexical borrowing has been furthered by her. Not only that, after determining all the data into the relevant subcategories, the researchers calculated the total number of each category and converted them into percentages to examine their occurrences. Not to forget, some of the French dialogues were also translated into English. This method is meant to give a clear explanation regarding the circumstance of the characters' actions in switching to French in their interaction process with each other. Eventually, this mechanism allowed the readers to have extensive exposure to the sociocultural in France.

\section{Results and Discussions}

This section will be discussing the finding towards the patterns and factors producing the code-switching phenomenon in the French Kissing novel as mentioned above. A descriptive analysis procedure towards 242 numbers of data consisting the French words or phrases was used to discuss the findings comprehensively. The data presented that all of the types of code-switching mentioned by Poplack (1980) are found in the selected text showed in Table 1.

Table 1: Types of code-switching in French Kissing novel

\begin{tabular}{|r|c|c|}
\hline Types of code-switching & Number & Percentage \\
\hline Intrasentential code-switching & 192 & $79.34 \%$ \\
\hline Intersentential code-switching & 33 & $13.64 \%$ \\
\hline Tag code-switching & 17 & $7.02 \%$ \\
\hline
\end{tabular}

From Table 1, we can examine that intrasentential code-switching was mostly being employed in the novel. Meanwhile, intersentential code-switching and tag code-switching were ranked second and third place, respectively. In the present study, this language phenomenon was determined both in the narrated text and the dialogues between the characters in the creative text. Furthermore, the findings will be discussed in-depth in the next sub-sections.

\section{Intrasentential Code-switching}

Intrasentential code-switching refers to the exchange of codes that occur in the same phrase or sentence. Maluleke (2019) asserts the switching takes place within a clause or sentence boundary which normally being used when the individuals changed the topic of their discussion. These are the most often types of code-switching being used by the novelist. Simultaneously, Poplack (1980) revealed intrasentential code-switching has a higher frequency of use than others. Her opinion has corresponded with the findings of this study as it is the dominant type found in this novel, constituting (79.34 \%) of occurrences. Next, this 
section will describe in detail some examples of dialogues using intrasentential codeswitching as shown by the examples below:

E1: "Mon chéri, you look stressed today,"

E2: "Last minute cancellations meant docked wages and docked wages meant I'd faced with a fin de moi difficile?

E3: "I'd only ever seen Sophie at Canet family gatherings in the past, never for a têteà-tête".

Based on E1, the utterance "mon chéri" is a French expression. According to Cambridge Dictionary, the utterance means "my dear or sweetheart" in English. Simultaneously, it presents the novelist's concern about the character, Nico, who is caring towards Mathilde that is not in a good mood. In detail, the novelist favors inserting switching in front of the dialogues to significance the intensity of Nico's concerns towards his lover. Moreover, it can also be influenced by the novelist's desire to make her writing looks fancier than using the corresponded English phrases. As Budi et al (2021). remarks, code-switching can be beneficial to enhance individuals' creativity in another language. Alternatively, it can enhance the readers' interest and attention towards her novel. Furthermore, in E2, the novelist employs "fin de moi difficile" as an idiom which can be interpreted as having difficulties at the end of the month. In this context, she was expressing the struggle of the character, Sally, living in a metropolitan city like Belleville, France when her wages were going to be deducted. Simultaneously, since the context of the novelist's storyline refers to a French-speaking country, the idiom is used in French rather than in English. Similarly, the findings also show some metaphorical expressions in the form of intrasentential codeswitching. According to Zhao (2014), metaphorical refers to a form of speech that developed a word or phrase to an object or action that does not correspond to any resemblance. In general, metaphor can also be functional to implies various imagery and perhaps emotion to a context as shown in E3. The "tête-à-tête" utterances mean face to face in English (MerriamWebster Dictionary). Based on the context, the novelist highlighted the character's thought, Sally, who is reminiscing about her meet up with Sophie which is usually at a family gathering than privately.

\section{Intersentential code-switching}

Meanwhile, intersentential code-switching occurs when there is an exchange between two languages horizontally in two different sentences. Likewise, Appel \& Muysken (1987) mentioned "this type of code-switching takes place after a sentence in the first language has been completed and continued the next sentence with another language". In general, it can be said that intersentential code-switching is the most complex form of codeswitching because individuals need to have a comprehensive understanding and ability to speak two or more distinct languages in a particular context. Based on the listed data, intersentential code-switching resorts as the second dominant type, with $(13.64 \%)$ of occurrences in total. Next, the paper will describe in-depth a few examples of dialogues developing intersentential code-switching as listed by the examples below:

E4: "Sally! Donne-moi dix minutes. I had a late night at the office and I'm afraid I overslept." 
E5: “Arrête tes caprices, Lila! Grandma and Granddad don't have any straws and you can drink perfectly well without one!"

E6: "I'Il take you home. T'inquiete pas, Sally, ça va aller..."

Based on example E4, we can see that the novelist wrote a complete French sentence as the first utterance and extended the next dialogues in English to sustain the key ideas in the first statement. The utterance, "Donne-moi dix minutes" means "give me ten minutes" in English. Consequently, in the given dialogues, the character, Nico is asking Sally to give him some time as he is overslept. In detail, Nico also wants to explain and significance that he has overslept due to his late-night at the workplace last night. This is in line with Puspitasari \& Anna (2020) who claims that an individual employed code-switching to recapitulate his/her idea with the others. Besides, in E5, the novelist switches as she aims to point up the characters' emotions, Sally towards her daughter, Lila. The utterance, "Arrête tes caprices," is defined as "stop your whims" according to Cambridge Dictionary. In detail, "Arrête" is functional to embark that Sally is displeased with Lila's insistence to drink with a straw in her parents' house. Meanwhile, despite the fact the novelist could utilize the corresponded words in English, she applies the French utterances to strongly enhance the character's disappointment or anger. This correlates with Anatoliy \& Li (2014) who assert the bilinguals will practice code-switching to demonstrates their emotions to others and it will usually encounter a new dimension. Furthermore, individuals that switch their languages frequently know the desire word they want to say in their primary language yet some words are more attainable in another language at the time especially when he/she has an imbalance level of emotions. For instance, in the context, Sally speaks out the French utterances as she wanted her bilingual daughter to know that she is very serious with her saying. Plus, the last utterance, E6, involves the implementation of French phrases in the last sentence. The switch involved the character, Nico's action in persuading Sally to come home with him. In detail, the utterances "T'inquiete pas, Sally, ça va aller..." means "Don't worry Sally, it's going to be okay" (Cambridge Dictionary), if we literally translated them in English. In this context, the novelist intended to give a clear picture of Nico's attempt to comfort Sally who did not trust him at the particular moment. This is in line with Gal as cited in Atkinson \& Kelly (2010) that exposed code-switching at the end of a sentence was not only productive to sum up the dialogue but may also induce any key features. For example, in the context, the novelist was more driven to use French instead of English for emphasizing purposes.

\section{Tag Code-switching}

This was the least type of code-switching applied in the novel, with just (7.02\%) of occurrences. Tag code-switching refers to the change in a language tag, precisely, phrase, word or both from one language to another. This corresponded to Appel \& Musyken (2006) that asserts tag code-switching refers to the individuals' deeds to tag a certain set of phrases from one language and transmitted them into an utterance that corresponds in another language. Hence, the following are some examples found in the novel:

E7: "Effectivement,' said Yves, who was listening in 'Who need Rendez-vous with you around, darling?

E8: "Merde! Nico was supposed to be bringing Lila over at ten."

E9: “Alors? Did you two have fun with Auntie Sophie?" 
Generally, the findings of the tag code-switching in the novel demonstrate this type of code-switching is a form of a non-syntactic constraint that can be put on almost everywhere and can be moved freely in a context without desecrating any grammatical rules between the involved languages, Romaine as cited in Azlan \& Narasuman (2012). This corresponded to the examples in E7 to E9 that presents the novelist's action to tag a few French words in front of the context. In the first two examples, E7 and E8, the utterance "Effectivement" and "Merde" which respectively means "It's true" and "Shit" according to (Cambridge Dictionary) was used as rhetorical expression. Next, the utterances displays in both examples are employed by the novelist to clear cut the reaction of Yves and Sally towards their current situations. For instance, in E7, Yves said "Effectivement"" to show his agreement towards his friend, whereas, Sally said "Merde" which can be classified as a curse word in French to support her anger towards Nico for bringing their daughter, Lila late. Moreover, in E9, the utterance "Alors?" means "Then?" (Cambridge Dictionary) has been tagged by the novelist as a conjunction to enhance the character's direction in her dialogue. For instance, Sally uses the utterance to ask about her daughter's experience with Sophie. As cited in Ariffin \& Galea (2009), tag codeswitching commonly takes place at boundaries as an amusing strategy to emphasize the utterance, gain others attention as well as furthering the action forward.

To sum up, the three types of code-switching as proposed by Poplack (1980) possess their features. Firstly, intersentential code-switching involves few complex French phrases that require comprehensive proficiency and understanding in both languages as Sally and Nico. Next, intrasentential code-switching that was discovered in the novel showed up French phrases that cannot be literally translated into English as they are frequently practices among the locals. Meanwhile, tag code-switching appears in the simple forms of words that are easy to alter. On top of that, each of the features has presented broaden ideas regarding the formation of each code-switching which will make it easier for everyone to gain new language, especially by practicing code-switching in their daily lives.

\section{Factors of Code-switching}

Furthermore, after analyzing the code-switching phenomenon contained in the creative work, the present study also discovered various factors that have influenced the characters to regulate code-switching in their dialogues. In detail, factors producing codeswitching that has been extracted from examining the novel are as follows: a) participants, solidarity and status, (b) topic, (c) switching for effective functions, (d) metaphorical switching and (e) lexical borrowing. In details, code-switching was applied by the novelist in different contexts. Consequently, the results of this analytical study showed this language phenomenon can be beneficial to expose the French local traditions and culture to the readers. The table below demonstrates different social factors governing the usage of codeswitching in the novel:

Table 2: Factors of Code-switching in French Kissing novel

\begin{tabular}{|c|c|c|}
\hline Factors of code-switching & Number & Percentage \\
\hline Switching for effective functions & 85 & $35.12 \%$ \\
\hline Topic & 78 & $32.23 \%$ \\
\hline Participants, solidarity and status & 42 & $17.36 \%$ \\
\hline Lexical borrowing & 21 & $8.68 \%$ \\
\hline Metaphorical switching & 16 & $6.61 \%$ \\
\hline
\end{tabular}


Table 2 displayed the frequency of different sociolinguistic factors found by analyzing the novel. Under the circumstances, switching for effective functions shown the most frequencies (35.12\%), followed by Topic showing (32.23\%) frequencies found in the data. Moreover, as presented in the table, the next factors behind this language phenomenon in the present study are as follows: Participants, solidarity and status (17.36\%), lexical borrowing (8.68 \%) and metaphorical switching (6.61\%), respectively. Precisely, the findings will be reviewed in-depth in the next sub-sections.

\section{Switching for Effective Functions}

The dominant factor-driven the usage of code-switching in the novel is to sustain the effective interactions process among the characters. In detail, rather than referential purposes, this language phenomenon can also be functional to express the affective message in a particular context. Therefore, below are some occurrences found in the novel:

E10: “Oui, oui... Tout va bien. My mother's returning Lila tomorrow evening.

\section{E11: "Je suis tellement épuisée'. I was up half of the night."}

E12: "Even if I doubted many people really found l'amour via Rendez-vous, I'd settle for a few interesting nights out to start with, or maybe even a fling."

The listed utterances in E10 to E12 review the novelist action to deliver affective messages through the usage of code-switching phenomenon among the characters. Firstly, it is not compulsory for an individual to perceive foreign codes but simply needed to capture the affective key features to achieve a range of interesting rhetorical effects. This correlates with Holmes (2008) who emphasizes on a certain occasion, an individual to understand the words to produce the affective effect in their dialogues as it can be attained through regional pronunciation. As listed in E11 and E12, the utterances "Oui, oui..." and "épuisée" which respectively means "Yes, yes..." and "exhausted" were the French regional words. In addition, the utterances "Oui, oui..." has embarked the usage of French tag in the conversation. In detail, Sally switches to French to deliver expression which clarified that her daughter, Lila will be given back by her mother the next day. Besides, the utterance "épuisée" has cleared up Delphine's action in switching her language to French to express her worn-out condition because she did not have a good sleep on the night which initially helps her to explain her lateness to Sally. Not only that, the findings showed the characters performing code-switching to incline the engagement within each other through expressive utterance. This corresponds with Ling et al (2014). who claims an individual usually enlarges this language phenomenon to enhance the intimacy with others. This can be seen in E10, the utterance "I'amour" which means "love" (Cambridge Dictionary), a well-known French word that was usually applied as a sentiment that emphasizes a relationship involving sexual intimacy. In detail, the novelist has used the utterance to engage Sally's perspective about finding love via an online website like Rendez-vous to other characters as well as the readers through amusement and intimate code.

\section{Topic}

In addition, the second distinguishable factor initiate in the listed dataset is the novelist apply code-switching to discuss indisputable topics through a particular language. 
Simultaneously, Holmes (2008) asserts that bilinguals/multilinguals occasionally preferred to discuss certain subject matter in one language rather than another. Below are some occurrences found in the novel:

E13: "Mummy, are the pain aux raisins in your bag now or for later?"

E14: "He taught Maths at a nearby lycée, he'd complimented me on high my French..."

E15: "In the cour de récréation the other day."

Generally, the listed utterances in E13 to E15, code-switching have been inserted by the novelist to provide some insights and knowledge about French sociocultural as the topic of discussion on the particular contexts. For instance, in E13, Lila has switched from English to French by altering the utterances "pain aux raisins" which refers to the French prominent pastry. Meanwhile, in E14 and E15, the novelist has underlined the general names for high school and playground through the utterances "lycée" and "cour de recreation", respectively. Consequently, this has partially quote French local terms by using this language phenomenon regardless for affective or referential purposes. Therefore, it can also be said that the switch has taken place as a set of quotation marks. According to Yusuf et al (2014), bilinguals often preferred to express particular referential content in one language besides another language. To sum up, the novelist has used French words to quote a certain phrase in the local culture which could not be interpreted using another language as explained in detail above.

\section{Participants, Solidarity and Status}

From the observations, the factor to acknowledge participants, solidarity and status were rank in third place in the novel. Simultaneously, code-switching was also being triggered by a change in a domain or social circumstances (Holmes, 2008). Hence, here are some occurrences analyzed from the novel:

E16: "C'est la maman de Lila Canet. I'm sorry to be arriving so late, but I had to deal with an urgent family matter on the phone..."

E17: "For a parent isolé, the parenting wasn't always the hardest part, in my opinion."

E18: "Would you like to have lunch with me sometime when Monsieur is away on business?"

In addition, the linguist also claims code-switching was beneficial to be used when there is a certain transformation in social dimension among a group of people. This language phenomenon was significant for an individual who wants to distinguish the status correlation between participants as well as the formality of the setting. Firstly, code-switching will be functional to address an arrival of a new participant to other members in a particular social context (Shin, 2010). Consequently, in E16, the utterance "C'est la maman de Lila Canet" that can be translated as "I'm Lila Canet's mom" (Cambridge Dictionary) was implemented by Sally to introduce herself to Lila's teacher who can speak English and French. Not only that, in the present study, it has been examining that code-switching arises when an individual desires to transform the tone in their conversation to present solidarity with others. This corresponds with Araya \& Espinoza (2013). and Holmes as cited in Narayan (2019) who asserts codeswitching was potentially being performed by an individual to emphasize their solidarity which includes signaling share ethnicity, as well as a social group under an acknowledge addresses within their locality. Therefore, as listed in E17, the utterance "parent isole," which 
means "single parents" (Collins Dictionary) has been allocating by the novelist to expose the term solidarity in France locality. Plus, this language phenomenon was also driven by the individuals' desires to reflect an individual's social status as well as to distinguish themselves from other social classes (Eldin, 2014). This corresponds with Holmes (2008) who underlines when there is a change in a social dimension like the formality of the setting or the individuals' status, the code-switching phenomenon is being used. For instance, an individual exchanges the formality of a language use depending on their addressees. Therefore, in E18, the utterance "Monsieur" which means "Mr. or Sir" (Cambridge Dictionary) is performed as the conventional French title of respect as well as a term to address a man. In the context, as an employee, Delphine alternated the French word to significance her formality when conversing about her superior with other characters.

\section{Lexical Borrowing}

Meanwhile, lexical borrowing showed as the fourth most used factor of codeswitching in the novel. According to Holmes (2008), this factor demonstrated code-switching that was developed due to linguistic incompetence in a language. Here are some occurrences initiate in the novel:

E19: "Chemistry, the elusive ingredient which had been missing from all my previous dates, was finally au rendez-vous."

E20: "I had a sudden flash of déjà vu, remembering the day I'd signed up, filled with doubt and trepidation."

E21: "I leaned forward to question the driver about the state of the traffic, half shouting to périphérique was all snarled up this morning."

Bilinguals often faced difficulties finding an appropriate word while they are performing code-switching (Paramasivam et al., 2020). Moreover, code-switching frequently implements when an individual faced a lack of vocabulary and needs to borrow from their native language (Horasan, 2014). This can be seen clearly in E19 to E21 which exhibits the novelist's action to borrow words from the second language, French which is the native language in France that was used as the main setting in her storyline. In detail, the novelist inserted French words to manifest certain views or describe an object which did not have equivalence in the code they are practicing. Firstly, in E19, the utterance "au rendez-vous'" means on a date (Collins Dictionary). The term "rendez-vous" is a famous French word that has already been borrowed into English with a change in spelling. In this context, the novelist makes use of the French word to describe Sally's perspective regarding her love experience. Whereas, in E20, the utterance "déjà vu" is a well-known French phrase that highlights a human's capability to recall a memory from the past (Rachna \& Adrian, 2000). Similarly, the phrase means the illusion of remembering a feeling that an individual has seen or heard before (Merriem-Webster Dictionary). In detail, the novelist has borrowed the French lexical to showcase Sally's feelings about a scene that she has experienced before. Besides, in E21, the utterance "périphérique" is the French term to represent the local demography. According to (Collins Dictionary) the utterance can be translated as a ring road which illustrates a road that moves around the edge of a town so the traffic does not have to pass the town center. 


\section{Metaphorical Switching}

Meanwhile, this factor of switching is usually developed at the intersentential codeswitching level. Not only that, this factor performed in a complex switch which highlights on associations of both languages. This corresponds with Holmes (2008) who asserts it is the results gained from a bilingual with an advanced level of languages comprehension which can be functional to enrich the communication process within a group of people. Below are some of the examples underlined from the novel:

E22: "and I imagined the aim had been to evoke the idea of a "coup de foundre,"

E23: "I wasn't sure how I felt about prolonged tête-à-tête."

E24: "Lila, c'est Nicolas tout craché, his mother Catherine never tired of saying."

Based on the listed data, this factor of code-switching displays a distinguishing interaction style by bilinguals' characters because it involved high proficiency in English and French where precisely, they will switch like a metaphor which aimed to enrich communication between each other. This corresponds to (Nur, 2016) who underlined metaphorical switching allows an individual to deliver a variety kind of linguistic resources available to embark on his/her interaction process. For example, in E22 the utterance "coup de founder" which means "love at the first sight" (Merriam-Webster Dictionary) is the famous French idiomatic expression that has been used to boost up Sally's background as a British girl who can practice French well in her conversation with other characters. Similarly, in E23, the utterance "tête-à-tête" which means "face-to-face" (Merriam-Webster Dictionary) has initially promoted the novelist's capability to use complex French phrases as a choice of linguistic resource in her creative writing. Not only that, metaphorical switching also allowed bilinguals to deliver ambivalent feelings about the subject matter in their conversation. As listed in E24, the utterance "c'est Nicolas tout craché" can be literally translated as "she's the spitting image of her father". In detail, French is used to describe Lila look alike her father, Nico while Sally expresses her annoyance regarding that matter.

\section{Conclusion}

Generally, the concept of code-switching which dedicates as the alternation between two different languages developed in the novel was the result of extensive bilingualism competence as well as social exposure among the characters. From the occurrences, the novelist, Catherine Sanderson establishes herself as initial cultural assertiveness by proficient use of more than one language in her writing. This can be proven by her attempt to use French linguistic items in her English novel which simultaneously enrich the cultural experience of France society. Her alternative was beneficial to globalize France's culture, traditions as well as heritage as English is a popular language used around the globe. There are three categories of code-switching that have been examined in the present study namely intrasentential codeswitching (79.34\%), intersentential code-switching with (13.64\%) and tag code-switching (7.02\%), respectively. The overall content analysis results emphasized each category of codeswitching found in the novel holds a certain degree of language capability which is from elementary terms, idiomatic lexical as well as complex expressions that were practiced among the local society. Simultaneously, it can be concluded that the degree of code-switching technique alternation among the characters is relatively higher. In detail, the choice of speaking French in the novel was driven by the background settings including the times, 
places as well as the characters' identities. Not only that, the result has also established the French language usage in the French Kissing novel was carried out by five distinguished reasons as explored by Holmes (2008). In particular, (1) switching for effective function encounter $35.12 \%$ of occurrences, (2) topic with $32.23 \%$ occurrences, (3) participants, solidarity and status with $17.36 \%$ occurrences, (4) lexical borrowing with $8.68 \%$ occurrences and (5) metaphorical switching with $6.61 \%$ occurrences, discretely. Not to forget, as a result of the analysis, the code-switching phenomenon was divided into diverse categories including references to customs and traditions, honorific titles and terms of respect, greeting and conversational phrases as well as geographic regions. Consequently, Catherine's alternative to apply code-switching in the selected novel has incorporated French textual and cultural elements in her creative writing. As the result, the code-switching phenomenon was proven as a significant communicative approach among the novelist, the characters as well as the readers.

\section{References}

Abu Bakar, M. S., \& Dahlan, N. A. D. (2017). Percampuran Kod Bahasa di dalam Filem: Satu Kajian Kualitatif Terhadap Filem J Revolusi (2017). e-Academia Journal, 7(2), 115. Retrieved from https://www.researchgate.net/publication/329398969_PERCAMPURAN_KOD_BAH ASA_DI_DALAM_FILEM_SATU_KAJIAN_KUALITATIF_TERHADAP_FILEM _J_REVOLUSI_2017

Eldin, A. (2014). Socio Linguistic Study of Code Switching of the Arabic Language Speakers on Social Networking. International Journal of English Linguistics, 4(6), 78-86. Retrieved from

https://www.ccsenet.org/journal/index.php/ijel/article/view/42623

Atkinson, D., \& Kelly, H. H. (2010). Codeswitching, identity and ownership in Irish radio comedy. Journal of Pragmatics, 43(1), 251-260. Retrieved from https://doi.org/10.1016/J.PRAGMA.2010.07.021

Anggraeni, D., \& Dewi, H. C. (2020). Code Switching Used by Boy William in Breakout Program on Net Tv, Deiksis 12(2), 132-139. Retrieved from https://journal.Ippmunindra.ac.id/index.php/Deiksis/article/view/4505/3113

Anatoliy, V. K., \& Li, W. (2015). The role of code-switching in bilingual creativity, International Journal of Bilingual Education and Bilingualism, 18(2), 153-169. Retrieved from https://doi.org/10.1080/13670050.2014.884211

Anggarukma, K. D. A., \& Winaya, I. (2019). The Analysis of Code Switching Found in the Novel "Critical Eleven". Journal of Art and Humanities, 23(1), 57-64. Retrieved from https://ojs.unud.ac.id/index.php/sastra/article/view/46965

Appel, R., \& Muysken, P. (1987). Language Contact and Bilingualism. Great Britain: Athenaeum Press Ltd.

Appel, R., \& Muysken, P. (2006). Language contact and bilingualism. Netherlands: Amsterdam University Press.

Araya, J. R., \& Espinoza, J. L. C. (2013). Code-switching in the EFL Classroom: Friend or Foe? Revista de Lenguas Modernas, 19, 375-391. Retrieved from https://repositorio.una.ac.cr/bitstream/handle/11056/19422/Code_Switching_in_th e_EFL.pdf?sequence=1\&isAllowed=y

Ariffin, K., \& Galea, R. S. (2009). Code-Switching As a Communication Device in Convesation. Language \& Society Newsletter, 5, 1-19. Retrieved from 
https://crisaps.it/wp-content/uploads/2020/05/2-Winter-2009-Ariffin.pdf

Cao, G. (2016). A Study of Code Switching in the Movie I Not Stupid Too. International Journal of Applied Linguistics and Translation, 2(6), 53-57. Retrieved from https://article.sciencepublishinggroup.com/html/10.11648.j.ijalt.20160206.11.html

Holmes, J. (2008). An introduction to sociolinguistics, $3^{\text {rd }}$ Ed. Harlow, United Kingdom: Pearson Education.

Horasan, S. (2014). Code-switching in EFL classrooms and the perceptions of the students and teachers. Journal of Language and Linguistic Studies, 10(1), 31-45. Retrieved from https://dergipark.org.tr/en/download/article-file/104767

Leavy, P. (2016). Fiction as Research Practice: Short Stories, Novellas, and Novels. $1^{\text {st }}$ Ed. New York: Routledge Publisher.

Maluleke, J. M. (2019). Using Code-Switching as an Empowerment Strategy in Teaching Mathematics to Learners with Limited Proficiency in English in South African Schools. South African Journal of Education, 39(3), 1-9. Retrieved from https://doi.org/10.15700/saje.v39n3a1528

Muhammed, S. J. (2017). Why and Where Do Bilinguals Code-Switch and What are The Functions of Doing This? 8th International Visible Conference on Educational Studies \& Applied Linguistics. Retrieved from https://conferences.tiu.edu.iq/vesal/wp-content/uploads/2018/01/31.pdf

Narayan, R. (2019). Code-switching as a Linguistic Resource in the Fijian ESL Classrooms: Bane or Boon? Journal of Language Teaching and Research, 10(3), 427-436. Retrieved from http://dx.doi.org/10.17507/jltr.1003.04

Nur, F. N. A. (2016). A Descriptive Analysis of English Indonesian Code Switching Spoken by The Teacher in The First Grade of MTsN Model Makassar. English, Teaching and Research Journal, 2(1), 82-95. Retrieved from http://journal.uin-alauddin.ac.id/index.php/Eternal/article/view/2365

Paramasivam. (2010). Codeswitching in Communication: A Sociolinguistic Study of Malaysian Secondary School Students. Pertanika Journal of Social Science and Humanities, 18(2), 407-415. Retrieved from https://citeseerx.ist.psu.edu/viewdoc/download?doi=10.1.1.232.1968\&rep=rep1\&ty pe $=$ pdf\#page $=214$

Puspitasari, R. D., \& Anna, D. (2020). Code Switching in Sarah Sechan Talk Show on NET TV. Utopía y Praxis Latinoamericana, 25(1), 462-470. Retrieved from https://www.redalyc.org/jatsRepo/279/27963086043/27963086043.pdf

Poplack, S. (1980). "Sometimes I'll start a sentence in English y termino en español: toward a typology of code-switching". Linguistics, 18(8) 581-618. Retrieved from https://doi.org/10.1515/ling.1980.18.7-8.581

Rachna, D., \& Adrian, P. (2000). Dej'a Vu: A User Study 'Using Images for Authentication. In Proceedings of the 9th USENIX Security Symposium. The USENIX Association. Retrieved from https://www.usenix.org/legacy/events/sec00/full_papers/dhamija/dhamija.pdf

Roslan, A. S. O. H. @ H. (2020). Code-Switching English-French in the Novel Petite Anglaise. International Journal of Academic Research in Business and Social Sciences, 10(6), 595-607. Retrieved from http://dx.doi.org/10.6007/IJARBSS/v10i6/7335

Sanderson, C. (2008). French Kissing. New York: Penguin Group. 
Shin, S.Y. (2010). The functions of Code-switching in a Korean Sunday School. Heritage Language Journal, 7(1) 91-115. Retrieved from https://doi.org/10.46538/hlj.7.1.5

Ningsih, S. O., \& Setiawan, T. (2021). Code Mixing and Code Switching in the "Yowis Ben" Movie: Sociolinguistic Study. International Journal of Linguistics, Literature and Translation. 4(4), 14-19. Retrieved from https://doi.org/10.32996/ijllt.2021.4.4.3

Tawfiq, H. B., \& Qararia, S. (2018). The Function of Code-Switching in Selma Dabbagh's Out of It. Advances in Language and Literary Studies, 9(2), 126-130. Retrieved from http://dx.doi.org/10.7575/aiac.alls.v.9n.2p.126

Wardaugh, R. (2006). Introduction to Sociolinguistics, $5^{\text {th }}$ Ed. Oxford: Blackwell Publishing.

Wang, H., \& Mansouri, B. (2017). Revisiting Code-Switching Practice in TESOL: A Critical Perspective. Asia-Pacific Edu Res, 26(4), 407-415. Retrieved from https://doi.org/10.1007/s40299-017-0359-9

Zhao, L. L. (2014). A study on metaphor and its differences between English and Chinese cultures. Canadian Social Science, 10(4), 101-105. Retrieved from https://core.ac.uk/download/pdf/236294505.pdf 